\title{
Sensory Stimulation Threshold: A Viable Tool to Improve the Outcome of Lumbar Facet Radiofrequency Denervation?
}

\author{
Weibin Shi ${ }^{1,2}$ \\ Renuka Rudra ${ }^{1,2}$ \\ To-Nhu Vu ${ }^{3}$ \\ Yuri Gordin (D) 1,2 \\ Ryan Smith ${ }^{1,2}$ \\ Allen R Kunselman ${ }^{4}$ \\ 'Department of Physical Medicine and \\ Rehabilitation, Penn State Health Milton \\ $S$ Hershey Medical Center, Penn State \\ College of Medicine, Hershey, PA, USA; \\ ${ }^{2}$ Penn State Hershey Rehabilitation \\ Hospital, Hummelstown, PA, USA; \\ ${ }^{3}$ Department of Anesthesiology \& \\ Perioperative Medicine, Penn State \\ Health Milton S Hershey Medical Center, \\ Penn State College of Medicine, Hershey, \\ PA, USA; ${ }^{4}$ Department of Public Health \\ Sciences, Penn State Hershey College of \\ Medicine, Hershey, PA, USA
}

Background: Sensory stimulation threshold (SST) has been used as a surrogate marker to target a nerve branch for radiofrequency (RF) denervation; however, the validity of SST as a prognostic marker is still under debate.

Objective: To assess whether lower SST values correlate with better outcomes of radiofrequency denervation for facetogenic low back pain.

Design: Prospective cohort study.

Patients: Sixty-seven patients who underwent radiofrequency denervation for low back pain.

Methods: Correlations, between the average percentage of pain relief from diagnostic medial branch block (MBB) and RF denervation procedure outcome, and between SST and RF denervation procedure outcome, were analyzed using Spearman correlation coefficient $\left(r_{s}\right)$. Wilcoxon rank sum test was performed to assess whether magnitude and duration of pain relief following RF denervation differed by the levels of SST $(<0.5$ and $\geq 0.5)$ or pain relief ( $<80 \%$ and $\geq 80 \%$ ) from diagnostic MBB.

Results: There was a positive correlation between pain relief after diagnostic MBB and pain relief 2 weeks after denervation $\left(r_{s} 0.31,95 \%\right.$ CI 0.08 to $\left.0.51, \mathrm{p}<0.01\right)$, but not between pain relief after MBB and pain relief 6 months after denervation, nor pain relief duration after denervation. There was a negative correlation between SST and pain relief 6 months after denervation $\left(r_{s}-0.41,95 \% \mathrm{CI}-0.59\right.$ to $\left.-0.18, \mathrm{p}<0.001\right)$. There was also a negative correlation between SST and pain relief duration after denervation $\left(r_{s}-0.33,95 \% \mathrm{CI}-0.53\right.$ to $-0.09, \mathrm{p}<0.01)$.

Conclusion: SST is a viable measurement with which to guide needle placement during RF denervation for lumbar facet pain, and enhances pain relief outcomes.

Keywords: sensory stimulation threshold, radiofrequency ablation, lower back pain, lumbar facet arthropathy, outcome

\section{Introduction}

Facet arthropathy is one of the most common causes of low back pain (LBP), accounting for about $30 \%$ of chronic LBP cases. ${ }^{1}$ Facet joint interventions are among the most commonly performed pain procedures. ${ }^{2,3}$ Therapeutic interventions for facet arthropathy include intraarticular facet joint injections and medial branch nerve radiofrequency (RF) denervation. RF denervation, a modality first introduced in the $1970 \mathrm{~s},{ }^{4}$ has the strongest supporting evidence for its durable efficacy. ${ }^{5-8}$ The efficacy of RF denervation is largely dependent on appropriate patient selection. Significant pain relief with diagnostic medial
Correspondence: Weibin Shi; To-Nhu Vu Email wshi@pennstatehealth.psu.edu; tonhuvu@pennstatehealth.psu.edu 
branch block (MBB) has previously been demonstrated to be a better tool for patient selection for subsequent RF denervation than intraarticular facet joint injection, and thus, dual $\mathrm{MBB}$ is often performed prior to RF denervation. ${ }^{3,9}$ However, the correlation between diagnostic MBB and RF denervation outcomes is still being defined, and a study by Cohen et al (2010) suggested that radiofrequency ablation without diagnostic blocks may be more cost-effective. ${ }^{10-12}$ The Facet Treatment Study (FACTS), a more recent randomized controlled clinical trial investigating the predictive value of facetogenic pain treatment, did not find that MBB was a better prognostic procedure than intraarticular injection prior to RF denervation, and leaves us wondering if diagnostic $\mathrm{MBB}$ is really a reliable prognostic or predictive tool of RF denervation outcome. $^{7}$

Sensory Stimulation threshold (SST), originally used as a safety measure to prevent inadvertent damage to motor nerves during RF denervation, has also been used as a surrogate marker to localize needle proximity to the target nerve branch. The magnitude of SST traditionally desired and/ or accepted is $\leq 0.5$ volts. Needle placement based on fluoroscopic landmarks alone could increase the chances of missing the intended nerves and cause damage to unintended structures due to normal anatomic variations in patients. ${ }^{13,14}$ Intuitively, a lower SST indicates a closer proximity of the electrode to the intended nerve and a better chance of thorough denervation, hence better outcomes. Yet sensory stimulation is not currently recommended in the Spine Intervention Society (SIS) Guidelines for RF denervation. ${ }^{15}$ Cohen et al (2011) found no significant relationship between SST and RF denervation outcomes. However, the authors themselves noted that participants' age and comorbidities might have affected the results of their study. ${ }^{16}$ Our study excludes patients with these comorbidities, such as peripheral polyneuropathy or radiculopathy, and aims to determine whether a lower SST correlates with better outcomes in patients undergoing lumbar facet RF denervation. We hypothesize that a lower SST will correlate with better pain relief, and increased duration of pain relief in patients undergoing lumbar facet RF denervation.

\section{Methods}

Permission to conduct this study was granted by the Institutional Review Board at our institution (STUDY00009162). All procedures and follow-up visits were performed between September 2014 and July 2020. Patients with a history and physical examination suggestive of facetogenic low back pain underwent diagnostic medial branch blocks to further confirm a diagnosis of facet arthropathy. Those who had positive results with dual diagnostic MBB (at least 50\% pain relief) and who subsequently underwent lumbar facet joint RF denervation, were screened for inclusion in the study. The electronic medical record used at our institution was utilized to collect patient data (age, duration of low back pain, documentation of facet arthropathy, percent of relief from MBB, SST during RF denervation, and pain relief from RF denervation). Patients included in the study were 18 years of age or older, had confirmed chronic lumbar facet joint pain of at least 3 months duration, had trialed and failed previous pharmacotherapy, physical therapy, and exercise, and had reported at least $50 \%$ pain relief with dual diagnostic MBB. All eighty-one patients who were screened met this inclusion criteria. Dual diagnostic MBB were performed by the same interventional pain physician who performed RF denervation in this study, and were performed using $0.5 \mathrm{~mL}$ of either $0.25 \%$ bupivacaine or $1 \%$ lidocaine at each target location. ${ }^{15}$ No superficial local anesthesia was used for MBB. Patients with neurological signs or symptoms suggestive of peripheral polyneuropathy or radiculopathy, contraindications for interventional procedures, psychiatric conditions, suspicion for secondary gain, involvement in litigation, who were on high-dose opioids, or those lost to follow-up after RF denervation were excluded from the study. Fourteen patients were excluded from the study. Sixty-seven patients satisfied both the inclusion and exclusion criteria for the study. Seven patients included in the study had a history of prior spine surgery. Two patients were lost to follow-up after the 2-week post RF denervation evaluation, and one patient died of COVID-19 a year after 6-month follow-up evaluation; these patients were also included.

RF denervation was performed at an outpatient surgery center by one interventional pain physician. Prior to procedure, patients were asked to report their pain on a numerical rating scale (NRS) between 0 and 10. Monitored anesthesia care (MAC) was utilized for the procedure. Under MAC, patients were awake, alert, and able to converse with the interventionalist. The target for needle placement was between the neck of the superior articular process and the superomedial aspect of the transverse process, not beyond the ventral border of the facet column. ${ }^{15}$ To target the L5 dorsal ramus, the needle was placed at the groove between the S1 articular process and the sacral ala. ${ }^{17}$ Optimal needle positioning was confirmed utilizing anteroposterior, oblique, and lateral fluoroscopic views. Then, a sensory electrical stimulation of $50 \mathrm{~Hz}$ was initiated at 0.1 volts and slowly 
titrated up by increments of 0.1 volts until the patient could identify the stimulation (sensation of tingling, buzzing, vibration, or concordant pain). At each target location, electrodes were adjusted to obtain the lowest SST. If a patient failed to perceive sensory stimulation at less than 0.3 volts, the lowest SST was accepted after at least 3 attempts of adjusting electrode placement. The average SST of all ablation sites was then documented as the SST for that individual patient. For most patients, determining the lowest SST took about one to two minutes per location/electrode. Motor stimulation of the multifidus muscle was then conducted at $2 \mathrm{~Hz}$ to ensure the absence of leg muscle activity. After satisfactory electrode placement, $1 \mathrm{~mL}$ of $1 \%$ lidocaine was injected through each cannula to anesthetize the target location. Denervation was then conducted at $80^{\circ} \mathrm{C}$ for 105 seconds utilizing a 20 -gauge probe with a $10 \mathrm{~mm}$ active tip. After denervation, $5 \mathrm{mg}$ of triamcinolone $(40 \mathrm{mg} / \mathrm{mL})$ was injected to presumably prevent post-denervation neuritis.

After RF denervation, patients followed up in 2 weeks and 6 months for evaluation of pain relief. The NRS numbers reported before and after denervation were used to calculate a percentage of pain relief. All patients were followed up until their pain returned (percentage of relief dropped to less than $50 \%$ ). The duration of pain relief from RF denervation was considered to be from the date of the RF denervation procedure, to the date at which pain relief dropped to less than $50 \%$.

\section{Statistical Analysis}

The correlations, between the average percentage of pain relief from diagnostic $\mathrm{MBB}$ and $\mathrm{RF}$ denervation outcome, and between SST and RF denervation outcome, were analyzed using correlation analysis procedure of $\mathrm{SAS}^{\circledR}$ Studio (Spearman correlation). Wilcoxon rank sum test was performed to analyze if the mean pain relief from RF denervation or if the mean duration of pain relief differed by the levels of
SST $(<0.5$ and $\geq 0.5)$ or by level of pain relief from diagnostic $\operatorname{MBB}(<80 \%$ and $\geq 80 \%)$. Alpha levels were set at 0.05 .

\section{Results}

Sixty-seven patients were included in this study based on the above inclusion and exclusion criteria (Table 1). Forty-eight patients were female, and nineteen were male. Gender was

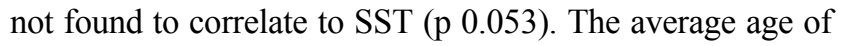
the patients was 55.19 years (SD 12.17, 95\% CI 52.22 to 58.16). The average percentage of pain relief from diagnostic MBB was $78.96 \%$ (SD 16.11, 95\% CI 75.03 to 82.88 ). The average SST was 0.46 volts (SD $0.09,95 \%$ CI 0.44 to 0.48 ). One patient failed to respond to sensory stimulation at $>1$ volt ( 0.68 volts on average) in one location; SST was documented as 1.0 volt at this location. The average pain relief after subsequent RF denervation was 77.39\% (SD 18.88, 95\% CI 72.78 to 81.99 ) at 2 weeks and $57.34 \%$ (SD 21.27, 95\% CI 52.03 to 62.66 ) at 6 months. The average duration of pain relief from $\mathrm{RF}$ denervation $(\geq 50 \%)$ was 9.47 months (SD $8.47,95 \%$ CI 7.35 to 11.59 ).

There was a positive correlation between pain relief after diagnostic MBB and pain relief 2 weeks after denervation $\left(r_{s} 0.31,95 \%\right.$ CI 0.08 to $\left.0.51, \mathrm{p}<0.01\right)$ (Table 2$)$. There was no significant correlation between pain relief after diagnostic MBB and pain relief six months after denervation ( $r_{s}$ coefficient $0.20,95 \%$ CI -0.05 to 0.42 , $\mathrm{p} 0.11)$ or pain relief duration after denervation $\left(r_{s} 0.22\right.$, $95 \%$ CI -0.03 to $0.44, \quad \mathrm{p} \quad 0.08$ ) (Table 2).

There was no correlation between SST and pain relief at two weeks after denervation $\left(r_{s} 0.017,95 \% \mathrm{CI}-0.26\right.$ to 0.22 , p 0.89) (Table 3 ). There was a negative correlation between SST and pain relief at six months after denervation $\left(r_{s}-0.41,95 \% \mathrm{CI}-0.59\right.$ to $\left.-0.18, \mathrm{p}<0.001\right)$, and a negative correlation between SST and pain relief duration after denervation $\left(r_{s}-0.33,95 \% \mathrm{CI}-0.53\right.$ to -0.09 , $\mathrm{p}<0.01$ ) (Table 3).

Table I Demographic and Clinical Outcome Summary

\begin{tabular}{|l|c|c|}
\hline & Mean \pm SD & Median (25 ${ }^{\text {th }}$ Percentile, 75 $^{\text {th }}$ Percentile) \\
\hline Age & $55.19 \pm 12.17$ & $52.00(45.00,66.00)$ \\
Block Relief (\%) & $78.96 \pm 16.11$ & $80.00(65.00,90.00)$ \\
SST (volt) & $0.46 \pm 0.09$ & $0.47(0.40,0.53)$ \\
2 Week Relief (\%) & $77.39 \pm 18.88$ & $80.00(70.00,90.00)$ \\
6 Month Relief (\%) & $57.34 \pm 21.27$ & $50.00(40.00,75.00)$ \\
Relief Duration (months) & $9.47 \pm 8.47$ & $7.00(5.00,11.00)$ \\
\hline
\end{tabular}

Abbreviations: Block relief: the percentage pain relief after diagnostic block; SST: sensory stimulation threshold; 2 week RFA relief: the percentage pain relief 2 weeks after denervation; 6 Month Relief: the percentage pain relief 6 months after denervation; relief duration: duration of pain relief from the RF denervation; $95 \% \mathrm{Cl}$ : $95 \%$ confidence interval; SD: standard deviation. 
Table 2 Correlation Between Pain Relief from Diagnostic Block and Denervation Outcome

\begin{tabular}{|l|c|c|c|c|}
\hline Variable & With Variable & N & Correlation Coefficient (95\% Confidence Interval) & p-value \\
\hline 2 Week Relief & Block Relief & 67 & $0.31(0.08,0.5 \mathrm{I})$ & 0.009 \\
6 Month Relief & Block Relief & 64 & $0.20(-0.05,0.42)$ & $0.1 \mathrm{I}$ \\
Relief Duration & Block Relief & 64 & $0.22(-0.03,0.44)$ & 0.08 \\
\hline
\end{tabular}

Abbreviations: Block relief, percentage pain relief after diagnostic block; 2 Week RFA relief, the percentage pain relief 2 weeks after denervation; 6 month relief, the percentage pain relief 6 months after denervation; relief duration, duration of pain relief from the RF denervation.

Table 3 Correlation Between Sensory Stimulation Threshold and Denervation Outcome

\begin{tabular}{|l|c|c|c|c|}
\hline Variable & With Variable & N & $\begin{array}{c}\text { Correlation Coefficient } \\
\text { (95\% Confidence Interval) }\end{array}$ & p-value \\
\hline Age & SST & 67 & $0.24(0.003,0.46)$ & 0.046 \\
2 Week Relief & SST & 67 & $-0.017(-0.26,0.22)$ & 0.89 \\
6 Month Relief & SST & 64 & $-0.41(-0.60,-0.18)$ & $<0.001$ \\
Relief Duration & SST & 64 & $-0.32(-0.53,-0.09)$ & 0.007 \\
\hline
\end{tabular}

Abbreviations: SST, sensory stimulation threshold; 2 Week RFA relief, the percentage pain relief 2 weeks after denervation; 6 month relief, the percentage pain relief 6 months after denervation; relief duration, duration of pain relief from the RF denervation.

The Wilcoxon Rank-Sum test showed that in comparison to patients with higher SST $(\geq 0.5)$, patients with lower SST $(<0.5)$ had a significant higher percentage pain relief 6 months after denervation, and with longer pain relief duration (P 0.001 and 0.005 respectively) (Table 5). There was no significant difference in pain relief at two weeks after denervation between patients with higher SST $(\geq 0.5)$ and those with lower SST $(<0.5)$ (Table 5). Patients with a higher percentage of pain relief from diagnostic MBB $(\geq 80 \%)$ had a significantly higher percentage of pain relief two weeks after denervation (P 0.05), but no significantly difference in pain relief six months after denervation or in pain relief duration (P 0.12 and 0.11 respectively) (Table 4).

\section{Discussion}

Since RF denervation of the medial branch of the dorsal ramus of the spinal nerve was successfully introduced as a treatment modality for lumbar facetogenic pain in the 1970s, it has become one of the most commonly performed pain procedures, with its efficacy supported by robust evidence. $^{5-8,18-20}$ The procedure has been standardized by the Spine Intervention Society. ${ }^{15}$ The rationale underlying RF denervation for lumbar facetogenic pain is dependent upon the assumption that elimination of nociceptive input from the nerve branches innervating a particular facet joint will alleviate pain. Thus, the proximity of the electrode to the targeted nerve branch during an attempted RF denervation should strongly correlate with that desired outcome.
In this study, patients experienced a broad range of pain relief in response to diagnostic MBB, ranging from the cutoff for inclusion (50\%) to complete resolution of pain (100\%). We know that the diagnostic MBB provides us with a relatively accurate quantification of facetogenic pain. The commonly used volume of injectate for a nerve block, $0.5 \mathrm{~mL}$, is more than enough to cover the intended nerve, ${ }^{21}$ thus the sensitivity of a nerve block is up to $100 \%$ with specificity of about $80 \%{ }^{22}$ There is about a $20 \%$ false positive rate, likely due to placebo effect or blockage of another pain source, such as myofascial pain. So, if a diagnostic lumbar MBB yields 50\% pain relief, it is likely that half of the overall low back pain originates from the facet joint that has been blocked. The subsequent RF denervation outcome should be consistent with the diagnostic nerve block if we truly ablate all of the intended nerve branches. Therefore, in the preceding example, we would expect around a $50 \%$ reduction in pain after RF denervation if our needle placement is accurate.

We hypothesized that a lower SST (inferring closer proximity of the probe to the intended nerve), would correlate with a better outcome after RF denervation. The results confirm our hypothesis, as lower SST was correlated with better pain relief at 6 months and with a longer duration of relief (P 0.001 and 0.005 respectively). The lack of correlation between pain relief from diagnostic block and $\mathrm{RF}$ denervation is consistent with some previous studies. ${ }^{10,11}$ While diagnostic block procedures are effective tools that allow for selection of patients for RF denervation, the 
Table 4 Wilcoxon Rank-Sum Test - Pain Relief from Diagnostic Block as Binary

\begin{tabular}{|c|c|c|c|c|}
\hline & $\begin{array}{l}\text { Block Relief } \\
\text { (Number of } \\
\text { Patients) }\end{array}$ & $\begin{array}{l}\text { Median }\left(25^{\text {th }} \text { Percentile, }\right. \\
\left.75^{\text {th }} \text { Percentile }\right)\end{array}$ & $\begin{array}{l}\text { Hodges-Lehmann Location Shift Estimate } \\
\text { (95\% Confidence Interval) }\end{array}$ & p-value \\
\hline \multirow[t]{2}{*}{2 Week Relief } & $<80 \%(39)$ & $75.0(57.5,87.5)$ & \multirow[t]{2}{*}{$-5.0(-20.0,0.0)$} & \multirow[t]{2}{*}{0.05} \\
\hline & $\geq 80 \%(28)$ & $80.0(75.0,100.0)$ & & \\
\hline \multirow[t]{2}{*}{6 Month Relief } & $<80 \%(36)$ & $50.0(40.0,70.0)$ & \multirow[t]{2}{*}{$-10.0(-20.0,0.0)$} & \multirow[t]{2}{*}{0.12} \\
\hline & $\geq 80 \%(28)$ & $50.0(45.0,80.0)$ & & \\
\hline \multirow[t]{2}{*}{ Relief Duration } & $<80 \%(36)$ & $6.0(4.0,10.0)$ & \multirow[t]{2}{*}{$-2.0(-5.0,0.0)$} & \multirow[t]{2}{*}{0.11} \\
\hline & $\geq 80 \%(28)$ & $7.0(5.0,12.0)$ & & \\
\hline
\end{tabular}

Abbreviations: Block relief, the percentage pain relief from diagnostic block; 2 Week RFA relief, the percentage pain relief 2 weeks after denervation; 6 month relief, the percentage pain relief 6 months after denervation; relief duration, duration of pain relief from the RF denervation.

Table 5 Wilcoxon Rank-Sum Test - Sensory Stimulation Threshold as Binary

\begin{tabular}{|c|c|c|c|c|}
\hline & $\begin{array}{l}\text { SST (Number of } \\
\text { Patients) }\end{array}$ & $\begin{array}{l}\text { Median }\left(25^{\text {th }} \text { Percentile, }\right. \\
\left.75^{\text {th }} \text { Percentile }\right)\end{array}$ & $\begin{array}{l}\text { Hodges-Lehmann Location Shift Estimate } \\
\text { (95\% Confidence Interval) }\end{array}$ & p-value \\
\hline \multirow[t]{2}{*}{2 Week Relief } & $\geq 0.5(25)$ & $80.0(60.0,90.0)$ & \multirow[t]{2}{*}{$0.0(-15.0,5.0)$} & \multirow[t]{2}{*}{0.45} \\
\hline & $<0.5(42)$ & $80.0(75.0,90.0)$ & & \\
\hline \multirow[t]{2}{*}{6 Month Relief } & $\geq 0.5(25)$ & $50.0(40.0,50.0)$ & \multirow[t]{2}{*}{$-25.0(-30.0,-10.0)$} & \multirow[t]{2}{*}{0.001} \\
\hline & $<0.5$ (39) & $70.0(50.0,80.0)$ & & \\
\hline \multirow[t]{2}{*}{ Relief Duration } & $\geq 0.5(25)$ & $6.0(4.0,7.0)$ & \multirow[t]{2}{*}{$-3.0(-1.0,-3.5)$} & \multirow[t]{2}{*}{0.005} \\
\hline & $<0.5(39)$ & $9.0(6.0,12.0)$ & & \\
\hline
\end{tabular}

Abbreviations: SST, sensory stimulation threshold; 2 week RFA relief, the percentage pain relief 2 weeks after denervation; 6 month relief, the percentage pain relief 6 months after denervation; relief duration, duration of pain relief from the RF denervation.

outcome of RF denervation is dependent upon the precision of targeting the intended nerve.

Our results at two-week follow-up did not suggest a correlation between lower SST and better pain relief. As described, the RF denervation was followed by injection of triamcinolone to the denervation area to presumably prevent post-denervation neuritis. This local steroid injection likely provided therapeutic benefit, as it covered the same area of diagnostic anesthetic, and confounded the 2-week follow-up results. This could further explain the correlation between diagnostic block and pain relief observed at 2-week follow-up. It has been confirmed that injection of steroid through the cannula after ablation but prior to its removal may reduce pain and discomfort following RFA, but not influence long-term follow-up results. ${ }^{23}$

There were a few patients in our study who reported greater pain relief from RF denervation than from diagnostic MBB (Appendix). This may at first be surprising as we assume a wider area of coverage by the anesthetic solution used in diagnostic block compared to ablation area in RF denervation. $^{21}$ However, RF denervation is theoretically more thorough and precise (if confirmed by SST) in blocking nociceptive input to the facet joint. Furthermore, we must consider the relatively low concentrations of anesthetic used in diagnostic blocks, $0.25 \%$ bupivacaine or $1 \%$ lidocaine.

\section{Limitations}

SST of $\leqslant 0.5$ volts is considered acceptable; ${ }^{3}$ therefore, when a SST of $\leqslant 0.5$ volts is yielded on first attempt, in practice, we would not make further attempts to find a lower SST. However, in order to find the lowest SST for each patient, we started our testing at 0.1 volts and slowly titrated up in increments of 0.1 volts. We set 0.3 volts as a checkpoint. At all locations for denervation, the lowest SST was accepted after at least 3 attempts unless the SST was lower than 0.3 volts $(0.1$ or 0.2 volts). The SSTs listed in our study are not necessarily the lowest for every medial branch targeted considering we did not test multiple electrode sites at 0.2 volts. Also, as Cohen 
et al pointed out in their study, ${ }^{16}$ for multiple nerve RF denervation procedures, simply averaging the SST of all targeted nerves may not be best practice as each facet joint may contribute unequally to overall pain. We should weigh the SST of each nerve proportionally to its pain contribution. However, we are limited in determining just how much each facet joint contributes to the overall axial low back pain.

There are myriad factors that confound SST. In this study, age was moderately correlated to SST (data not included). While we tried to exclude patients with confounding conditions such as neuropathy, it is not possible to entirely factor out all such cases. We were unable to standardize the sedatives used by anesthesiology during the RF denervation procedure. Additionally, we could not fully eliminate factors such as patient-specific body composition which influences the response to sedation, nor account for variable tolerance of RF denervation procedure which may impact its quality or precision. For RF denervation, local anesthetic use prior to needle insertion was not necessarily uniform; for patients who had lower pain tolerance, local anesthetic was injected into the paraspinal muscles, and not just limited to subcutaneous tissue. Unintentional anesthetization of medial branches could theoretically occur if injectate spreads deep to the paraspinal muscles.

Finally, pain level and percentage of pain relief is subjective and varies with activity level of the patient. Additionally, a patient who wants to have RF denervation may report a higher percentage of pain relief from the diagnostic medial branch block. In our experience, it is not uncommon that patients report different outcomes to different providers, whether consciously or subconsciously.

\section{Conclusions}

SST is a viable tool with which to guide needle placement during medial branch RF denervation for lumbar facetogenic pain, and a lower SST may improve outcomes.

\section{Ethics}

Permission to conduct this study was granted by the Institutional Review Board at Penn State University (STUDY00009162) with confirmation of patient informed consent and compliance with the Declaration of Helsinki.

\section{Disclosure}

Mr Allen Kunselman reports stock ownership in Merck and Novavax, outside the submitted work. The authors report no other potential conflicts of interest for this work.

\section{References}

1. DePalma MJ, Ketchum JM, Saullo T. What is the source of chronic low back pain and does age play a role? Pain Med. 2011;12 (2):224-233. doi:10.1111/j.1526-4637.2010.01045.x

2. Manchikanti L. The growth of interventional pain management in the new millennium: a critical analysis of utilization in the medicare population. Pain Phys. 2004;7(4):465-482. doi:10.36076/ppj.2004/ $7 / 465$

3. Cohen SP, et al. Consensus practice guidelines on interventions for lumbar facet joint pain from a multispecialty, international working group. Reg Anesth Pain Med. 2020;45(6):424-467.

4. Shealy CN. Percutaneous radiofrequency denervation of spinal facets. Treatment for chronic back pain and sciatica. J Neurosurg. 1975;43(4):448-451. doi:10.3171/jns.1975.43.4.0448

5. Bogduk N. Evidence-informed management of chronic low back pain with facet injections and radiofrequency neurotomy. Spine J. 2008;8 (1):56-64. doi:10.1016/j.spinee.2007.10.010

6. Lord SM, Barnsley L, Wallis BJ, et al. Percutaneous radio-frequency neurotomy for chronic cervical zygapophyseal-joint pain. $N$ Engl $J$ Med. 1996;335(23):1721-1726. doi:10.1056/NEJM199612053 352302

7. Cohen SP, Doshi TL, Constantinescu OC, et al. Effectiveness of lumbar facet joint blocks and predictive value before radiofrequency denervation: the Facet Treatment Study (FACTS), a randomized, controlled clinical trial. Anesthesiology. 2018;129(3):517-535. doi:10.1097/ALN.0000000000002274

8. Nath S, Nath CA, Pettersson K. Percutaneous lumbar zygapophysial (Facet) joint neurotomy using radiofrequency current, in the management of chronic low back pain: a randomized double-blind trial. Spine (Phila Pa 1976). 2008;33(12):1291-7; discussion 1298. doi:10.1097/BRS.0b013e31817329f0

9. Cohen SP, et al. Medial branch blocks or intra-articular injections as a prognostic tool before lumbar facet radiofrequency denervation: a multicenter, case-control study. Reg Anesth Pain Med. 2015;40 (4):376-383. doi:10.1097/AAP.0000000000000229

10. Holz SC, Sehgal N. What is the correlation between facet joint radiofrequency outcome and response to comparative medial branch blocks? Pain Phys. 2016;19(3):163-172. doi:10.36076/ppj/ 2019.19.163

11. Cohen SP, Strassels SA, Kurihara C, et al. Establishing an optimal "cutoff" threshold for diagnostic lumbar facet blocks: a prospective correlational study. Clin J Pain. 2013;29(5):382-391. doi:10.1097/ AJP.0b013e31825f53bf

12. Cohen SP, Williams KA, Kurihara C, et al. Multicenter, randomized, comparative cost-effectiveness study comparing 0,1 , and 2 diagnostic medial branch (facet joint nerve) block treatment paradigms before lumbar facet radiofrequency denervation. Anesthesiology. 2010;113(2):395-405. doi:10.1097/ALN.0b013e3181e33ae5

13. Bogduk N. The innervation of the lumbar spine. Spine (Phila Pa 1976). 1983;8(3):286-293. doi:10.1097/00007632-198304000-00009

14. Lau P, Mercer S, Govind J, et al. The surgical anatomy of lumbar medial branch neurotomy (facet denervation). Pain Med. 2004;5 (3):289-298. doi:10.1111/j.1526-4637.2004.04042.x

15. Bogduk N. International Spine Intervention Society, Practice Guidelines for Spinal Diagnostic and Treatment Procedures. Second ed. San Francisco: International Spine Intervention Society; 2013:xii, 684.

16. Cohen SP, Strassels SA, Kurihara C, et al. Does sensory stimulation threshold affect lumbar facet radiofrequency denervation outcomes? A prospective clinical correlational study. Anesth Analg. 2011;113 (5):1233-1241. doi:10.1213/ANE.0b013e31822dd379

17. Dreyfuss P, Schwarzer AC, Lau P, et al. Specificity of lumbar medial branch and L5 dorsal ramus blocks. A computed tomography study. Spine (Phila Pa 1976). 1997;22(8):895-902. doi:10.1097/00007632199704150-00013 
18. Dreyfuss P, Halbrook B, Pauza K, et al. Efficacy and validity of radiofrequency neurotomy for chronic lumbar zygapophysial joint pain. Spine (Phila Pa 1976). 2000;25(10):1270-1277. doi:10.1097/ 00007632-200005150-00012

19. MacVicar J, Borowczyk JM, MacVicar AM, et al. Lumbar medial branch radiofrequency neurotomy in New Zealand. Pain Med. 2013;14(5):639-645. doi:10.1111/pme.12000

20. Schneider BJ, Doan L, Maes MK, et al. Systematic review of the effectiveness of lumbar medial branch thermal radiofrequency neurotomy, stratified for Diagnostic methods and procedural technique. Pain Med. 2020;21(6):1122-1141. doi:10.1093/pm/ pnz349
21. Wahezi SE, Alexeev E, Georgy JS, et al. Lumbar medial branch block volume-dependent dispersion patterns as a predictor for ablation success: a cadaveric study. PM R. 2018;10(6):616-622. doi:10.1016/j.pmrj.2017.11.011

22. Manchikanti L, Singh V, Pampati V. Are diagnostic lumbar medial branch blocks valid? Results of 2-year follow-up. Pain Phys. 2003;6 (2):147-153. doi:10.36076/ppj.2003/6/147

23. Dobrogowski J, Wrzosek A, Wordliczek J. Radiofrequency denervation with or without addition of pentoxifylline or methylprednisolone for chronic lumbar zygapophysial joint pain. Pharmacol Rep. 2005;57(4):475-480.

\section{Publish your work in this journal}

The Journal of Pain Research is an international, peer reviewed, open access, online journal that welcomes laboratory and clinical findings in the fields of pain research and the prevention and management of pain. Original research, reviews, symposium reports, hypothesis formation and commentaries are all considered for publication. The manuscript

Submit your manuscript here: https://www.dovepress.com/journal-of-pain-research-journal management system is completely online and includes a very quick and fair peer-review system, which is all easy to use. Visit http:// www.dovepress.com/testimonials.php to read real quotes from published authors. 